\title{
Effect of a Soluble Cocoa Fiber-Enriched Diet in Zucker Fatty Rats
}

\author{
David Sánchez, Leila Moulay, Begoña Muguerza, ${ }^{2}$ Mar Quiñones, \\ Marta Miguel, ${ }^{1,3}$ and Amaya Aleixandre ${ }^{1}$ \\ ${ }^{1}$ Departamento de Farmacología, Faculta de Medicina, Universidad Complutense; ${ }^{3}$ Instituto de Fermentaciones Industriales, \\ Consejo Superior de Investigaciones Científicas, Madrid; and ${ }^{2}$ Natraceutical Group, Valencia, Spain
}

\begin{abstract}
The effects of a soluble cocoa fiber (SCF) were studied in Zucker fatty rats. Two groups of Zucker fatty rats were fed the following diets: standard diet and 5\% SCF-enriched diet. A group of Zucker lean rats fed the standard diet was used for results comparison with obese Zucker animals. Solid and liquid intakes, body weight, plasma glucose, lipid profile, and systolic (SBP) and diastolic (DBP) blood pressure were recorded weekly. At the end of the experimental period insulin was determined, and fat apparent digestibility (FAD) and insulin resistance were calculated. The Zucker fatty rats fed 5\% SCF-enriched diet showed less weight gain and food intake than those fed the standard diet. The group fed the fiber-enriched diet showed lower values of the total cholesterol/high-density lipoprotein cholesterol ratio and triglyceride levels than the standard group. FAD was also lower in the fiber group. Both SBP and DBP were decreased. In addition, SCF reduced plasma glucose and insulin, and as a consequence the insulin resistance was also decreased. Our data demonstrate that SCF resulted in an improvement of the studied risk factors associated with cardiometabolic disorders.
\end{abstract}

KEY WORDS: • cocoa $\bullet$ metabolic syndrome $\bullet$ soluble fiber $\bullet$ Zucker rats

\section{INTRODUCTION}

$\mathbf{T}$ HE METABOLIC SYNDROME is emerging as one of the most important public health problems in the world. This metabolic disorder can be defined as a cluster of health problems, caused by genetic and environmental factors, whose common fundamental pathogenic component is resistance to insulin. ${ }^{1-3}$ It has been reported that dietary fiber appears to be particularly beneficial in the control of the most of the metabolic disturbances clustered in the metabolic syndrome. ${ }^{4,5}$

Dietary fiber is the name given to groups of components present in foods of vegetable origin (cereals, fruit, vegetables, and pulses) that are not broken down by human digestive enzymes. ${ }^{6}$ Dietary fiber can be subdivided or classified into insoluble and soluble fiber. The principal beneficial effects of a fiber-rich diet in patients with metabolic syndrome are prevention of obesity, improved glucose levels, and control of the profile of blood lipids. ${ }^{7}$ It has also been suggested that dietary fiber may favor the control of arterial blood pressure. ${ }^{8}$ There is therefore a growing interest in discovering new sources of natural fiber that may be used as functional ingredients to obtain foods with properties that are beneficial to health.

Cocoa (Theobroma cacao L.) is widely used in the chocolate industry. Much attention has been paid in recent

Manuscript received 25 May 2009. Revision accepted 29 August 2009.

Address correspondence to: Dra. M. Miguel, Instituto de Fermentaciones Industriales, Consejo Superior de Investigaciones Científicas, C/Juan de la Cierva, 3, 28006, Madrid, Spain, E-mail: marta.miguel@ifi.csic.es years to cocoa and cocoa products because of their potential benefits on health. Cocoa husk is a waste product from the chocolate industry. This by-product is frequently used as secondary source of theobromine and caffeine but could also offer a valuable and cheap source of dietary fiber. A product rich in soluble cocoa fiber (SCF) was obtained by a patented enzymatic process from cocoa husk. ${ }^{9}$ In a previous work the beneficial effect of $10 \%$ SCF in hypercholesterolemic Sprague-Dawley rats was demonstrated; the results showed an improvement in lipid profile and an important decrease of body weight. $^{10}$

Zucker fatty rats are considered the best-known and most widely used experimental model of genetic obesity. These animals present also dyslipidemia, mild glucose intolerance, and hyperinsulinemia, alterations similar to those that appear in the human metabolic syndrome. These animals can, in fact, be also considered a model of resistance to insulin, whereas Zucker lean rats are insulin sensitive and normoinsulinemic and have a normal tolerance of glucose. ${ }^{11-14}$

The aim of the present study was to evaluate in an experimental animal model the effect of SCF on the main cardiometabolic risk factors that characterize the human metabolic syndrome (obesity, impaired glucose tolerance, dyslipidemia, and hypertension). In the present study, 5\% SCF-enriched diet was fed to Zucker fatty rats. Therefore we evaluate in these animals the effect of a lower dose of SCF than the one used in the previous study. ${ }^{10}$ A group of Zucker lean rats was used for results comparison with nonobese Zucker animals. 


\section{MATERIALS AND METHODS}

\section{General protocol}

Twenty female 8-week-old Zucker fatty rats weighing 260-275 g and 10 female 8-week-old Zucker lean rats weighing 150-175 g, purchased from Charles River Laboratories (Barcelona, Spain), were used in this study. The Zucker fatty rats were randomly divided into two groups of 10 animals that were fed the following diets until week 15 of life: standard diet or 5\% SCF-enriched diet. The lean Zucker rats were only used to provide normal values in the Zucker strain, and they were in turn fed the standard diet until week 15 of life. During the experimental period the animals were maintained at a temperature of $23^{\circ} \mathrm{C}$, with 12-hour light/dark cycles, and were fed ad libitum with free access to water.

Food intake, water intake, and body weight gain were recorded on a weekly basis in the different groups of rats. Plasma total cholesterol, plasma cholesterol transported by high-density lipoproteins (HDL cholesterol), triglycerides, and glucose were also measured on a weekly basis. Because the usual biochemical procedures to determine the cholesterol transported in plasma by low-density lipoproteins in Zucker rats are not reliable, we calculated the ratio total cholesterol/HDL cholesterol. This ratio is known in clinical practice as the "atherogenic index." In order to carry out all the determinations mentioned above, blood extractions from the jugular vein were performed weekly in the rats after an overnight fasting.

Systolic blood pressure (SBP) and diastolic blood pressure (DBP) were measured weekly in the rats during the experimental period, by the tail cuff method. ${ }^{15}$ The original technique for measuring arterial blood pressure using the tail cuff method provides only SBP values; however, the equipment used in this study (LE 5001 pressure meter, Letica Scientific Instruments, Barcelona), has a high-sensitivity pulse transducer coupled with an accurate microprocessor program, thus allowing us to distinguish between SBP and DBP. Before the measurements, the rats were kept at $38^{\circ} \mathrm{C}$ for 10-15 minutes to make the pulsations of the tail artery detectable. Arterial blood pressure measurements were performed at the same time of day (between 9 a.m. and 1 p.m.) in order to avoid the influence of the circadian cycle, and the values of SBP and DBP were obtained by estimating the average reading of five measurements.

During the last week of treatment the animals were placed in metabolic cages. Feces were collected, and the weight was recorded. They were pooled, sealed in Falcon tubes (BD, Franklin Lakes, NJ, USA), and frozen until analysis. The samples were dried to constant weight, and fat content was determined by the Soxhlet method using petroleum ether. ${ }^{16}$ The fat apparent digestibility (FAD) was calculated for each animal as $100 \times$ (fat intake - fat output)/fat intake. Fat intake was in turn estimated taking into account the composition of diets, and the fat content in feces was considered the fat output.

At the end of the experimental period all the rats were sacrificed by decapitation after an overnight fasting. Blood was obtained from the sacrificed rats to carry out the same biochemical determinations that we had performed weekly, and the corresponding values of atherogenic index were also calculated. In addition, plasma insulin was determined. Moreover, fasting plasma concentrations of both glucose and insulin were used to calculate indices of insulin resistance (homeostasis model assessment-insulin resistance [HOMA-IR] and insulin secretion [HOMA- $\beta$ ]) with the following formulae ${ }^{17}$ : HOMA-IR $=$ fasting insulin (in $\left.\mu \mathrm{U} / \mathrm{mL}\right) \times$ fasting glucose (in $\mathrm{m} M$ ) $/ 22.5$; HOMA- $\beta=20 \times$ fasting insulin (in $\mu \mathrm{U} / \mathrm{mL}$ ) /[fasting glucose (in $\mathrm{m} M$ ) - 3.5].

In this study, all the experiments were performed as authorized for scientific research (European Directive 86/609/ CEE and Royal Decree 223/1988 of the Spanish Ministry of Agriculture, Fisheries and Food).

\section{Diets}

Two synthetic diets were used in this study (Table 1). They were prepared by Harlan Interfauna Ibérica, Barcelona. The first one (AIN-93M purified Rodent Diet) was a standard diet that provides the nutrients required by adult rats according to the National Research Council guidelines. ${ }^{18}$ The other diet contained 5\% SCF (from SCF product provided by Natraceutical Group, Valencia, Spain). The two diets were prepared and formulated to provide the same amount of protein (14\%), fat (4\%), and carbohydrates (72\%) and therefore the same energy value.

\section{Analytical procedures}

Blood samples were collected into tubes containing lithium heparin as anticoagulant. These samples were centrifuged at 2,500 $\mathrm{g}$ for 20 minutes at $4{ }^{\circ} \mathrm{C}$ to obtain the plasma, which was divided into aliquots and kept frozen at $-80^{\circ} \mathrm{C}$ until analysis.

Table 1. Composition of the Diets

\begin{tabular}{lcc}
\hline & \multicolumn{2}{c}{$g / 100 g$ dry weight } \\
\cline { 2 - 3 } & Standard diet & $5 \%$ SCF \\
\hline Protein & 14 & 14 \\
Casein & 14 & 11.8 \\
Fat & 4 & 4 \\
Soybean oil & 4 & 3.36 \\
Carbohydrate & 72 & 72 \\
Sucrose & 10 & 8.70 \\
Dextrin & 15.5 & 13.49 \\
Cornstarch & 46.56 & 40.53 \\
Powdered cellulose & 5 & 5 \\
SCF product & 0 & 12.15 \\
tert-Butylhydroquinone & 0.0008 & 0.0008 \\
AIN 93 mineral mixture & 3.5 & 3.5 \\
AIN 93 vitamin mixture & 1 & 1 \\
L-Cystine & 0.18 & 0.18 \\
Choline bitartrate & 0.25 & 0.25 \\
Energy (kJ/100 g) & 1,589 & 1,589 \\
\hline
\end{tabular}

The carbohydrate substitution in the experimental diets was formulated at the expense of sucrose, dextrin, and cornstarch proportionally.

${ }^{a} \mathrm{SCF}$ product contains protein $(17.92 \%)$ and fat $(5.26 \%)$; the exact amount of soluble fiber is $41.16 \%$. 
The lipid profile (total cholesterol, HDL cholesterol, and triglycerides) and plasma glucose were assayed by using enzymatic and colorimetric methods with commercial kits (Roche Diagnostics S.L., Barcelona). The different concentrations of these variables were determined spectrophotometrically with a Hitachi (Roche Farma, Madrid, Spain) model 911 autoanalyzer (wavelength, $700 \mathrm{~nm}$ ). The plasma insulin concentration was spectrophotometrically quantified by using an ultrasensitive rat insulin enzyme immunoassay kit (Mercodia AB, Uppsala, Sweden) with a Thermomax microplate reader (MolecularDevices, Sunnyvale, CA, USA). The absorbance was measured at $450 \mathrm{~nm}$.

\section{Statistical analysis}

The results are expressed as mean \pm SEM values for a minimum of eight rats and were analyzed by a two-way analysis of variance, using GraphPad (San Diego, CA, USA) Prism version 4 software. In addition, to assess the effect of time within each treatment and to compare the variables that were only determined at the end of the experimental period, some data were also analyzed by a one-way analysis of variance. Differences between the groups were assessed by the Bonferroni test. Differences between the means were considered to be significant with $P<.05$.

\section{RESULTS}

\section{Food and liquid intakes and body weight}

Food intake throughout the study was significantly higher in the Zucker fatty rats fed the standard diet than in the lean rats and the Zucker fatty rats fed the SCF-enriched diet (Fig. 1A). Water intake was significantly higher in the group fed the fiber-enriched diet than in the Zucker fatty rats fed the standard diet and the lean rats (data not shown).

The groups of Zucker fatty rats fed the standard diet and the SCF-enriched diet progressively gained weight during the experimental period. However, the weight gain of the group fed the fiber-enriched diet was significantly lower than the body weight of the rats fed the standard diet. The lean group gained also progressively weight during the experimental period. Nevertheless, as expected, these animals exhibited a significantly reduced weight compared to the Zucker fatty rats (Fig. 1B).

\section{Plasma biochemistry}

Total cholesterol and HDL cholesterol were significantly higher in the two groups of Zucker fatty rats than in the Zucker lean rats. The group of Zucker fatty rats fed the SCFenriched diet showed the higher values of total and HDL cholesterol (Fig. 2A and B). The total cholesterol/HDL cholesterol ratio, termed the atherogenic index in clinical practice, of the rats fed the standard diet was significantly higher than this same ratio in the rats fed the SCF-enriched diet or the lean rats along the study (Fig. 2C).

Plasma triglycerides were higher in the Zucker fatty rats than in the Zucker lean rats during all the experimental period. The group of Zucker fatty rats fed the standard diet
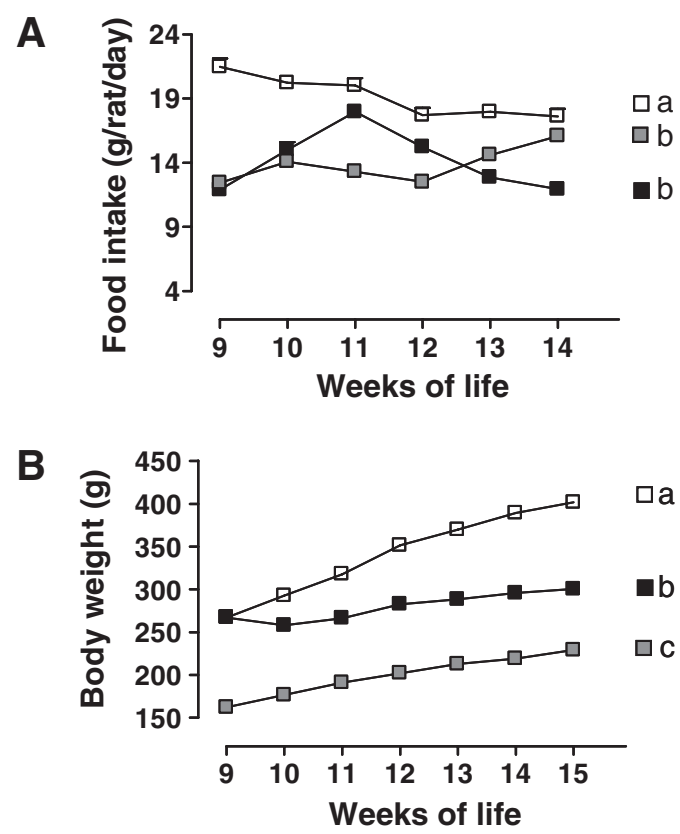

FIG. 1. (A) Food intake and (B) body weight of different groups of rats: Zucker fatty rats fed the standard diet $(\square)$, Zucker fatty rats fed 5\% SCF-enriched diet ( $\square$ ), and Zucker lean rats fed the standard diet ( $\square$ ). Data are mean values \pm SEM for a minimum of eight rats. Different letters represent statistically significant differences $(P<.05)$

showed an increase in plasma triglycerides throughout the study, but the group fed the SCF-enriched diet revealed a significant decrease in plasma triglycerides compared to this group (see Fig. 2D).

At the beginning of the experimental period, fasting blood glucose was markedly higher in the two groups of Zucker fatty rats than in the Zucker lean rats, but the consumption of SCF-enriched diet resulted in a significant decrease of fasting blood glucose along the study (Fig. 2E).

Plasma insulin levels were higher in the Zucker fatty rats fed the standard diet than in the Zucker lean rats or the Zucker fatty rats fed the SCF-enriched diet. The consumption of the SCF-enriched diet resulted in a significant reduction in plasma insulin level to the extent that no differences were observed between this group and the lean control group (Fig. 3A). The Zucker fatty rats fed the standard diet exhibited the highest values of HOMA-IR and HOMA- $\beta$. The SCF-enriched diet caused a significant decrease in both indices. In fact, HOMA$\beta$ values were similar in the Zucker fatty rats fed the SCFenriched diet and in the Zucker lean rats (Fig. 3B and C).

\section{Fat in feces}

The fat content in the feces was lower and the FAD was higher in the Zucker fatty rats compared to the Zucker lean rats. Fat excretion in the feces increased in the Zucker fatty rats fed the SCF-enriched diet (Table 2). Significant differences were also observed between the FAD of the Zucker fatty rats fed the 5\% SCF-enriched diet and the Zucker fatty rats fed the standard diet (Fig. 4). 


\section{A}

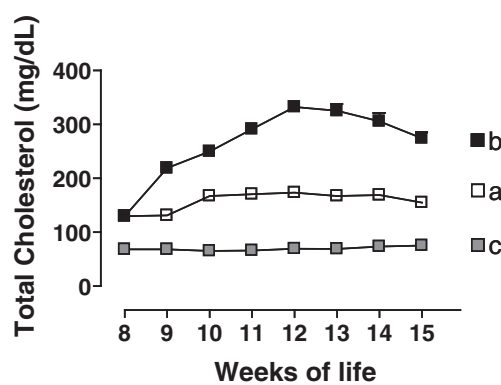

D
B

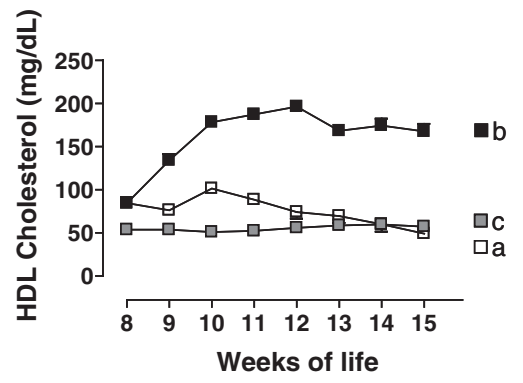

C

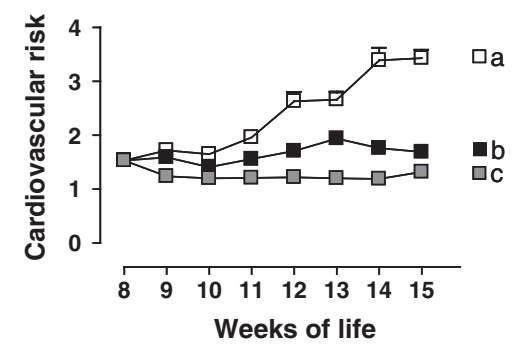

E
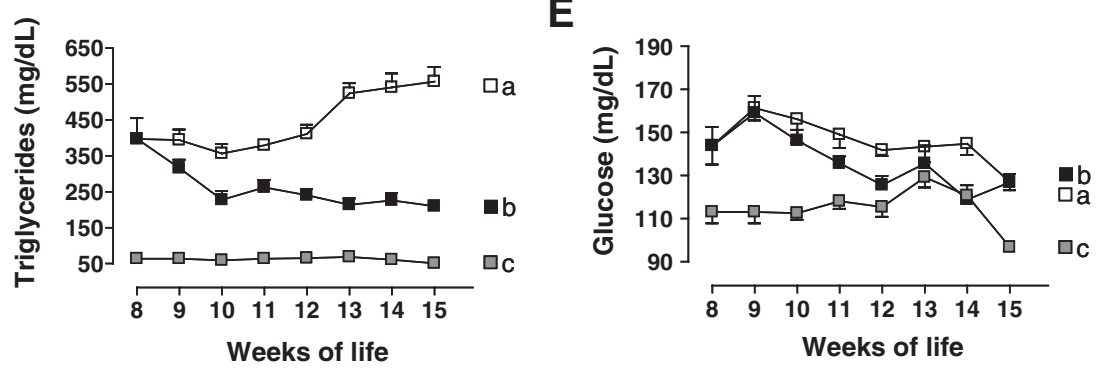

FIG. 2. (A) Plasma total cholesterol, (B) plasma HDL cholesterol, (C) total cholesterol/HDL cholesterol ratio, (D) plasma triglycerides, and (E) plasma glucose of different groups of rats: Zucker fatty rats fed the standard diet ( $\square$ ), Zucker fatty rats fed 5\% SCF-enriched diet ( $\square$ ), and Zucker lean rats fed the standard diet ( $\square)$. Data are mean \pm SEM values for a minimum of eight rats. Different letters represent statistically significant differences $(P<.05)$.
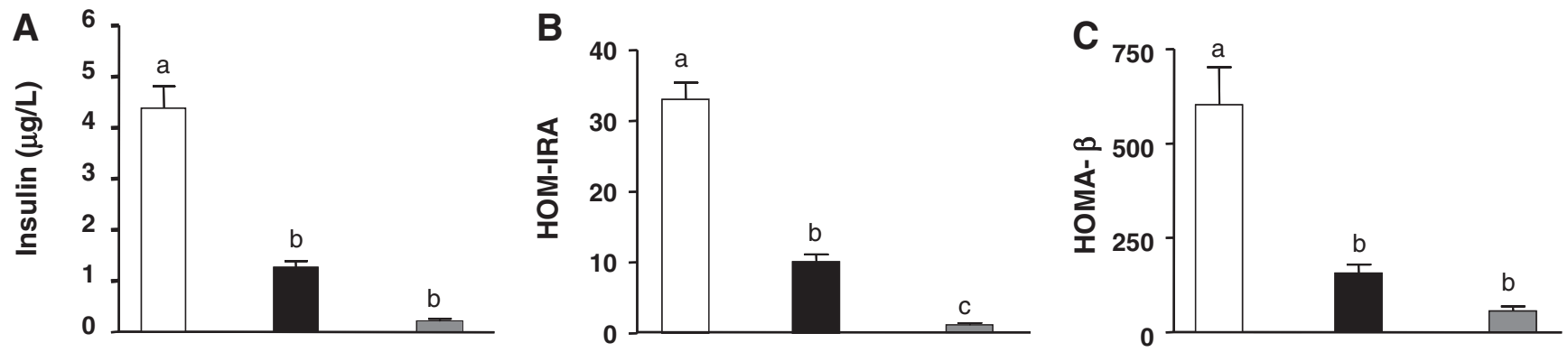

FIG. 3. Histograms of (A) plasma insulin, (B) HOMA-IR value, and (C) HOMA- $\beta$ value of different groups of rats at the end of the experimental period: Zucker fatty rats fed the standard diet $(\square)$, Zucker fatty rats fed 5\% SCF-enriched diet ( $\square$ ), and Zucker lean rats fed the standard diet ( $\square$ ). Data are mean \pm SEM values for a minimum of eight rats. Different letters represent statistically significant differences $(P<.05)$.

Table 2. Fecal Characteristics of Zucker Rats FED DifFEREnT Diets

\begin{tabular}{cccc}
\hline & $\begin{array}{c}\text { Fatty } \\
\text { standard }\end{array}$ & $\begin{array}{c}\text { Fatty } \\
5 \% \text { SCF }\end{array}$ & $\begin{array}{c}\text { Lean } \\
\text { standard }\end{array}$ \\
\hline Feces (g/day) & & & \\
Wet weight & $1.19 \pm 0.27^{\mathrm{a}}$ & $1.44 \pm 0.14^{\mathrm{ac}}$ & $2.06 \pm 0.06^{\mathrm{acd}}$ \\
Dry weight & $0.41 \pm 0.16^{\mathrm{a}}$ & $0.71 \pm 0.28^{\mathrm{a}}$ & $1.94 \pm 0.06^{\mathrm{b}}$ \\
$\%$ water in feces & $65.55^{\mathrm{a}}$ & $50.35^{\mathrm{ab}}$ & $5.83^{\mathrm{c}}$ \\
\% fat in feces & $0.27^{\mathrm{a}}$ & $0.93^{\mathrm{b}}$ & $2.6^{\mathrm{d}}$
\end{tabular}

Data are mean \pm SEM values for a minimum of eight rats.

${ }^{\text {abcd }}$ Different letters represent statistically significant differences $(P<.05)$.

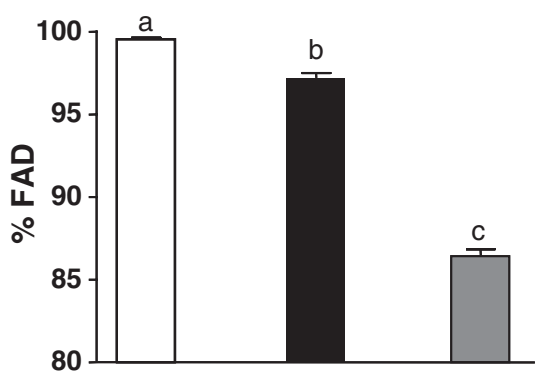

FIG. 4. Histograms of percentage FAD of different groups of rats in the last week of the experimental period: Zucker fatty rats fed the standard diet $(\square)$, Zucker fatty rats fed 5\% SCF-enriched diet (ם), and Zucker lean rats fed the standard diet $(\square)$. Data are mean \pm SEM values for a minimum of eight rats. Different letters represent statistically significant differences $(P<.05)$. 


\section{Blood pressure}

SBP and DBP throughout the study were significantly higher in the Zucker lean rats than in the Zucker fatty rats. The SBP and DBP values in the Zucker fatty rats fed the SCF-enriched diet were significantly lower than the corresponding values in the Zucker fatty rats fed the standard diet (Fig. 5).

\section{DISCUSSION}

Zucker fatty rats are the best-known and most widely used rat model of genetic obesity, and these animals are also considered as a good experimental model to study different alterations that characterize the metabolic syndrome. ${ }^{19,20}$ This disorder is becoming an important public health problem in western societies, and it is considered as a high-risk situation for cardiovascular disease. Many epidemiological studies have documented that nutritional factors, including fiber intake, may decrease the prevalence of this patho$\operatorname{logy} .^{21,22}$ In the present study, Zucker fatty rats were fed SCF, a soluble fiber that had previously demonstrated a hypocholesterolemic effect in rats fed cholesterol-rich diet, ${ }^{10}$ in order to assess the potentiality of this fiber in modulating some parameters related to the metabolic syndrome. The present study demonstrates that the intake of SCF-enriched diet is useful in the prevention of the main abnormalities clustered in the metabolic syndrome, including obesity, dyslipidemia, and glycemic profile.
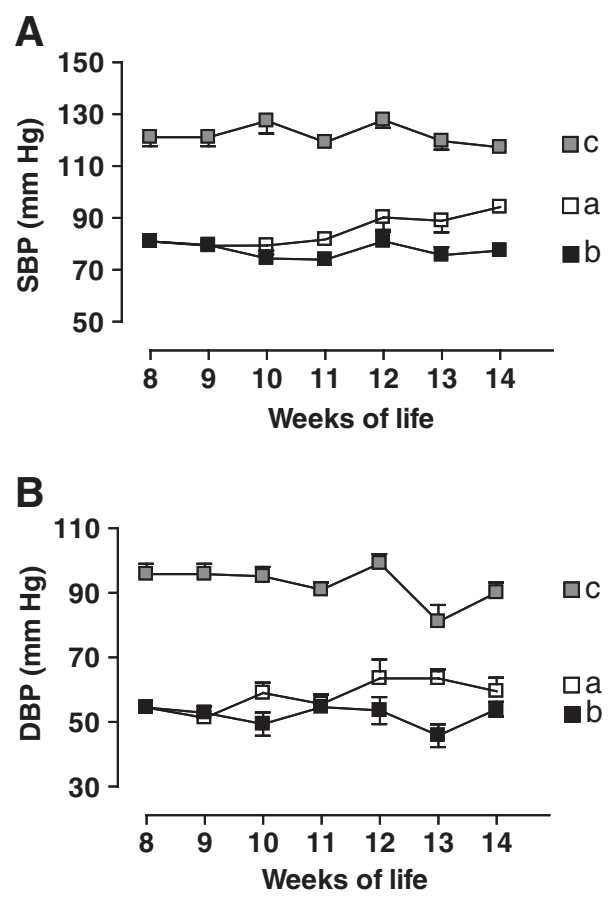

FIG. 5. (A) SBP and (B) DBP of different groups of rats: Zucker fatty rats fed the standard diet $(\square)$, Zucker fatty rats fed $5 \%$ SCFenriched diet ( $\square$ ), and Zucker lean rats fed the standard diet ( $\square$ ). Data are mean \pm SEM values for a minimum of eight rats. Different letters represent statistically significant differences $(P<.05)$.
This study even describes a slight blood pressure-lowering effect of SCF.

In the present study, the intake of soluble fiber resulted in a reduction of food body weight. Some researchers also reported a reduced body weight when high fiber diets were consumed. ${ }^{5}$ Pittler and Ernst ${ }^{23}$ in 2004 carried out a systematic review to assess the evidence from different studies on the effectiveness of dietary supplements in reducing body weight. In this review, data on the following dietary supplements were identified: chitosan, chromium picolinate, Ephedra sinica, Garcinia cambogia, glucomannan, guar gum, hydroxylmethylbutyrate, Plantago psyllium, pyruvate, yerba maté, and yohimbe. The reviewed studies provide some encouraging data, but Pittler and Ernst ${ }^{23}$ concluded that the evidence for most dietary supplements as aids in reducing body weight was not convincing. Nevertheless, in the present study, a marked reduction in body weight gain when SCF is fed was observed. These findings agree with the previous reported study using the same product. ${ }^{10}$

Soluble fiber can exhibit an effect on weight gain through different mechanisms. The reduced food intake observed in the rats fed SCF-enriched diet would indicate that a satiating effect was operating in these animals. According to different researchers, the reduction in appetite by dietary fiber could be a consequence of a mechanical intestinal distension and/ or as well delaying carbohydrate digestion and glucose absorption. The reduced glycemic and insulin responses could prolong satiety and thus reduce energy consumption. ${ }^{24-27}$ The low food intake and the glucose and insulin levels obtained in the rats fed SCF-enriched diet would support that these mechanisms would be also involved in the effects of this fiber on the weight management. The above-mentioned results may suggest that SCF could be used to control obesity, which is considered as a major risk factor for type 2 diabetes. ${ }^{28}$

The high total cholesterol levels observed in the animals fed SCF seem be an apparent consequence of the increased levels of HDL cholesterol. Nowadays, the beneficial effects of elevated HDL cholesterol levels are evident. It is worth noting that a highly significant decrease in triglyceride levels during the study was observed in the rats fed the SCF-enriched diet. The improvement of the lipid profile observed in this study when SCF was administered is in agreement with the results of other studies carried out with different fibers in rats ${ }^{10,29-31}$ and in humans. ${ }^{32}$ The presence of cocoa polyphenols in SCF could also explain the good results obtained in this group in the lipid profile. The total polyphenols and antioxidant capacity of SCF have been previously reported. ${ }^{10}$ The values are $23.9 \pm 0.11 \mathrm{mg} / \mathrm{g}$ and $569 \pm 76 \mathrm{mmol}$ of Trolox equivalents/g of dry matter for total polyphenols and oxygen radical absorbance capacity, respectively. In addition, the analysis of profile of flavan-3-ols showed an important amount of monomers of low molecular weight related to the functional properties of cocoa polyphenols. The reported values for catechin, epicatechin, and procyanidins B1 and B2 were $0.088 \pm 0.002,0.100 \pm 0.003$, $0.093 \pm 0.002$, and $0.039 \pm 0.007 \mathrm{mg} / \mathrm{g}$ of dry matter, 
respectively. ${ }^{10}$ In fact, increased HDL cholesterol and decreased triglyceride levels have been reported after the intake of dark chocolate or cocoa extracts rich in cocoa polyphenols. ${ }^{33}$

The present results demonstrate that the Zucker fatty rats digest fat much better than the Zucker lean rats. The obese animals eliminate much less fat in their feces than their lean counterparts. Therefore, the observed increase in FAD in Zucker fatty rats could be a mechanism involved in the obese condition of this strain. The decrease in FAD observed in the SCF-fed group suggests a decrease of cholesterol intestinal absorption. This could be another mechanism involved in the hypocholesterolemic effect of SCF observed in this study. The possible mechanisms involved in the hypocholesterolemic effect of dietary fiber are controversial, but the low fat absorption as a possible mechanism of action to justify the improvement of the lipid profile has been previously reported in animals ${ }^{34}$ and humans. ${ }^{35,36}$

In this study we have also observed a significant decrease in plasma glucose and in insulin levels in the Zucker fatty rats fed the SCF-enriched diets. In fact, the values of fasting blood glucose in the SCF-fed group during the last weeks of the study were quite similar to the values of the lean group. The reduction in insulin concentrations in the rats fed the fiber-enriched diet is in accordance with results previously described by other authors. ${ }^{31,37,38}$ Actually, fiber consumption remained significantly associated with fasting insulin. ${ }^{25} \mathrm{~A}$ link of low insulin concentrations and the reduction in body weight gain has been previously described, ${ }^{24,25,27}$ and this connection could even explain the decrease of body weight observed in the rats fed the fiberenriched diet. According to the low fasting glucose and insulin values obtained, the HOMA-IR was reduced in the group fed the fiber-enriched diet. These results are in agreement with other authors who reported that the intake of dietary fiber was inversely associated with HOMA-IR. ${ }^{21,39}$ The improvement of glucose homeostasis noted in our study in the fiber-fed group could be associated with the low glucose uptake induced by SCF. As a consequence of the low blood glucose levels, the pancreatic secretor capacity would be reduced, producing a lesser amount of insulin. This hypothesis would be confirmed by the assessed low HOMA- $\beta$ and insulin values obtained in the SCF-fed group. Therefore, SCF exhibited a beneficial effect on glucose homeostasis when it was consumed by Zucker fatty rats, and this effect was likely due to the blood glucose reduction produced by this fiber in these animals.

It is well established that blood pressure in Zucker fatty rats is lower between 8 and 12 weeks of life than in their lean counterparts, and this fact was also corroborated in our study. However, it has been described that from week 24 of life this phenomenon is inverted, and the Zucker fatty rats show elevated blood pressure levels compared with the lean animals. ${ }^{19}$ Therefore, the Zucker fatty rats could be considered as prehypertensive animals. ${ }^{40,41}$ Even if the animals used in this study were not a typical hypertensive rat model, we observed a slight decrease in blood pressure from 3-4 weeks in the rats fed SCF. It has been described that fiber intake could be implicated in the control of hypertension, ${ }^{30,42}$ and significant changes in SBP and DBP have been reported with fiber supplementation in hypertensive and older humans. ${ }^{43}$ In some studies, however, 8 weeks of fiber intake was required to obtain a blood pressure-lowering effect. ${ }^{44}$ The loss of weight and the improvement of insulin resistance are frequently associated with a decrease in blood pressure ${ }^{45-47}$ The decrease in food intake, body weight, and insulin resistance produced by SCF could be related with the blood pressure-lowering effect observed. In addition, this effect could be also due to the presence of small quantities of polyphenols in SCF. ${ }^{10}$ In fact, an amount of these antioxidant compounds as small as $30 \mathrm{mg} /$ day has been demonstrated to reduce arterial blood pressure in humans. ${ }^{48}$ To corroborate the potential antihypertensive effect of SCF, we are currently conducting some studies in spontaneously hypertensive rats, which constitute an accepted experimental model for human essential hypertension. The long-term intake of SCF clearly attenuates the development of hypertension in these animals (authors' unpublished data).

Overall, the results obtained point out that SCF may modulate parameters that appear altered in the metabolic syndrome such as body weight, glycemia, insulinemia, lipids, and blood pressure. It seems possible that dietary percentages of SCF lower than that used in the present study will also exhibit beneficial health effects in preventing risk factors associated with cardiometabolic disorders. The development of a new source of natural fiber from a waste product from the chocolate industry as cocoa husk could also offer a valuable and cheap source of dietary fiber and would allow more flexible applications in the food industry. In addition, the difference in the chemical structure of SCF and other fibers, responsible for their physical properties, and also the presence of cocoa polyphenols may explain the good results obtained with SCF. All this could justify the use of this fiber from this source relative to other sources. Additional studies with SCF are necessary to completely elucidate the mechanism(s) involved in the modulation of the parameters studied. In any case, in order to incorporate SCF as a functional food ingredient for obese patients and/or patients with the metabolic syndrome, its efficiency and safety in these patients should be determined.

\section{ACKNOWLEDGMENTS}

This study was supported by Natraceutical Group (206/ 2006 U.C.M. Project). We also thank Manuel Bas Caro, technician in pharmacology, for his excellent care of the rats and control of the diets in the different groups of animals. M.M. is the recipient of a Ramon y Cajal contract from MICINN.

\section{AUTHOR DISCLOSURE STATEMENT}

L.M. and B.M. are employees of Natraceutical Group. D.S., M.Q., M.M., and A.A. declare no competing financial interests exist. 


\section{REFERENCES}

1. Reaven G: Role of insulin resistance in human disease. Diabetes 1988;37:1595-1607.

2. Cameron AJ, Shaw JE, Zimmet PZ: The metabolic syndrome: prevalence in worldwide populations. Endocrinol Metab Clin North Am 2004;33:351-375.

3. Ford ES: Prevalence of the metabolic syndrome defined by the International Diabetes Federation among adults in the US. Diabetes Care 2005;28:2745-2749.

4. Davy BM, Melby CL: The effect of fiber-rich carbohydrates on features of Syndrome X. J Am Diet Assoc 2003;103:86-96.

5. Delzenne NM, Cani PD: A place for dietary fibre in the management of the metabolic syndrome. Curr Opin Clin Nutr Metab Care 2005;8:636-640.

6. De Vries JW, Prosky L, Li B, Cho S: Historical perspective of defining dietary fiber. Cereal Foods World 1999;44:367-369.

7. Galisteo M, Duarte J, Zarzuelo A: Effects of dietary fibers on disturbances clustered in the metabolic syndrome. J Nutr Biochem 2008;19:71-84.

8. Aleixandre A, Miguel M: Dietary fiber in the prevention and treatment of metabolic syndrome. Critical Rev Food Sci Nutr 2008;48:905-912.

9. Moulay L, Sniderman Z, Ibarra A, Martí Bartual V: Method of preparing a highly-soluble cocoa extract [in Spanish]. Patent WO/ 2006/117416 (PCT/ES2005/000377). September 11, 2006.

10. Ramos S, Moulay L, Granado-Serrano AB, Vilanova O, Muguerza B, Goya L, Bravo L: Hypolipidemic effect in cholesterol-fed rats of a soluble fiber-rich product obtained from cocoa husks. $\underline{J \text { Agric }}$ Food Chem 2008;56:6985-6993.

11. Zucker TF, Zucker LM: Hereditary obesity in the rat associated with high serum fat and cholesterol. Proc Soc Exp Biol Med 1962; 110:165-171.

12. Zucker LM, Antoniades HN: Insulin and obesity in the Zucker genetically obese rat "fatty." Endocrinology 1963;90:1320-1330.

13. Stern J, Johnson PR, Greenwood MRC, Zucker LM, Hirsch J: Insulin resistance and pancreatic insulin release in the genetically obese Zucker rat. Proc Soc Exp Biol Med 1972;139:66-69.

14. Kasiske BL, O'Donell MP, Keane WF: The Zucker rat model of obesity, insulin resistance, hyperlipidemia, and renal injury. Hypertension 1992;19:110-115.

15. Buñag RD: Validation in awake rats of a tail-cuff method for measuring systolic pressure. J Appl Physiol 1973;34:279-282.

16. Official Methods of Analysis, Vol. 2, $16^{\text {th }}$ revised edition. Association of Official Analytical Chemists, Washington, DC, 1990.

17. Matthews DR, Hosker JP, Rudenski AS, Naylor BA, Treacher DF, Turner RC: Homeostasis model assessment: insulin resistance and $\beta$-cell function from fasting plasma glucose and insulin concentration in man. Diabetologia 1985;28:412-419.

18. National Research Council: Guide for the Care and Use of Laboratory Animals. NIH Publication Number 85. U.S. Government Printing Office, Washington, DC, 1985, p. 23.

19. Kurtz TW, Morris RC, Pershadsingh HA: The Zucker fatty rat as a genetic model of obesity and hypertension. Hypertension 1989; 13:896-901.

20. Aleixandre de Artiñano A, Miguel Castro M: Experimental rat models to study the metabolic syndrome. Br J Nutr 2009;102: 1246-1253.

21. McKeown NM, Meigs JB, Liu S, Saltzman ES, Wilson PW, Jacques PF: Carbohydrate nutrition, insulin resistance, and the metabolic syndrome in the Framingham Offspring Cohort. Diabetes Care 2004;27:538-546.

22. Esposito K, Ciotola M, Giugliano D: Mediterranean diet and the metabolic syndrome. Mol Nutr Food Res 2007;51:12681274.

23. Pittler MH, Ernst E: Dietary supplements for body-weight reduction: a systematic review. Am J Clin Nutr 2004;79:529536.

24. Fernandez ML, Sun DM, Tosca MA, McNamara DJ: Citrus pectin and cholesterol interact to regulate hepatic cholesterol homeostasis and lipoprotein metabolism: a dose-response study in guinea pigs. Am J Clin Nutr 1994;59:869-878.

25. Ludwig DS, Pereira MA, Kroenke CH, Hilner JE, Van Horn L, Slattery ML, Jacobs DR Jr: Dietary fiber, weight gain, and cardiovascular disease risk factors in young adults. JAMA 1999;282: $1539-1546$.

26. Jenkins DJ, Kendall CW, Axelsen M, Augustin LS, Vuksan V: Viscous and nonviscous fibres, nonabsorbable and low glycaemic index carbohydrates, blood lipids and coronary heart disease. Curr Opin Lipidol 2000;11:49-56.

27. Liu S, Willett WC, Manson JE, Hu FB, Rosner B, Colditz G: Relation between changes in intakes of dietary fiber and grain products and changes in weight and development of obesity among middle-aged women. Am J Clin Nutr 2003;78:920-927.

28. Adams KF, Schatzkin A, Harris TB, Kipnis V, Mouw T, BallardBarbash R, Hollenbeck A, Leitzmann MF: Overweight, obesity and mortality in a large prospective cohort of persons 50 to 71 years old. $N$ Engl J Med 2006;355:763-768.

29. Daubioul C, Rousseau N, Demeure R, Gallez B, Taper H, Declerck B, Delzenne N: Dietary fructans, but not cellulose, decrease triglyceride accumulation in the liver of obese Zucker fa/fa rats. J Nutr 2002;132:967-973.

30. Galisteo M, Sanchez M, Vera R, González M, Anguera A, Duarte J, Zarzuelo A: A diet supplemented with husks of Plantago ovata reduces the development of endothelial dysfunction, hypertension, and obesity by affecting adiponectin and TNF-alpha in obese Zucker rats. J Nutr 2005;135:2399-2404.

31. Sánchez D, Muguerza B, Moulay L, Hernández R, Miguel M, Aleixandre A: High methoxilated pectin improves insulin resistance and other cardiometabolic risk factors in Zucker fatty rats. J Agric Food Chem 2008;56:3574-3581.

32. Anderson JW, Davidson MH, Blonde L, Brown WV, Howard WJ, Ginsberg H, Allgood LD, Weingand KW: Long-term cholesterol-lowering effects of psyllium as an adjunct to diet therapy in the treatment of hypercholesterolemia. Am J Clin Nutr 2000;71:1433-1438.

33. Cooper KA, Donovan JL, Waterhouse AL, Williamson G: Cocoa and health: a decade of research. Br J Nutr 2008;99:1-11.

34. Kesaniemi YA, Tarpila S, Miettinen TA: Low vs high dietary fiber and serum, biliary, and fecal lipids in middle-aged men. $\underline{A m}$ J Clin Nutr 1990;51:1007-1012.

35. Chandalia M, Garg A, Lutjohann D, von Bergmann K, Grundy SM, Brinkley LJ: Beneficial effects of high dietary fiber intake in

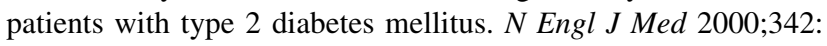
1392-1398.

36. Fernández ML: Distinct mechanisms of plasma LDL lowering by dietary fiber in the guinea pig: specific effects of pectin, guar gum, and psyllium. J Lipid Res 1995;36:2394-2404.

37. Tagliaferro V, Cassader M, Bozzo C, Pisu E, Bruno A, Marena S, Cavallo-Perin P, Cravero L, Pagano G: Moderate guar-gum 
addition to usual diet improves peripheral sensitivity to insulin and lipaemic profile in NIDDM. Diabetes Metab 1985;11: 380-385.

38. Fukagawa NK, Anderson JW, Hageman G, Young VR, Minaker KL: High-carbohydrate, high-fiber diets increase peripheral insulin sensitivity in healthy young and old adults. Am J Clin Nutr 1990;52:524-528.

39. Lau C, Faerch K, Glumer C, Tetens I, Pedersen O, Carstensen B, Jørgensen T, Borch-Johnsen K; Inter99 Study: Dietary glycemic index, glycemic load, fiber, simple sugars, and insulin resistance: the Inter99 study. Diabetes Care 2005;28:1397-1403.

40. Koletsky S: Pathologic findings and laboratory data in a new strain of obese hypertensive rats. Am J Pathol 1975;80:129-140.

41. Ernsberger P, Nelson DO: Refeeding hypertension in dietary obesity. Am J Physiol 1988;254:R47-R55.

42. Obata K, Ikeda K, Yamasaki M, Yamori Y: Dietary fiber, psyllium, attenuates salt-accelerated hypertension in stroke-prone spontaneously hypertensive rats. J Hypertens 1998;16:19591964.
43. Streppel MT, Arends LR, van 't Veer P, Grobbee DE, Geleijnse JM: Dietary fiber and blood pressure: a meta-analysis of randomized placebo-controlled trials. Arch Intern Med 2005;165: $150-156$.

44. Whelton SP, Hyre AD, Pedersen B, Yi Y, Whelton PK, He J: Effect of dietary fiber intake on blood pressure: a meta-analysis of randomized, controlled clinical trials. J Hypertens 2005;23:475-481.

45. Julius S, Valentini M, Palatini P: Overweight and hypertension: a 2-way street? Hypertension 2000;35:807-813.

46. Di Nardo F, Burattini R, Cogo CE, Faelli E, Ruggeri P: Agerelated analysis of insulin resistance, body weight and arterial pressure in the Zucker fatty rat. Exp Physiol 2009;94:162-168.

47. Edelson GW, Sowers JR: Insulin resistance in hypertension: a focused review. Am J Med Sci 1993;306:345-347.

48. Grassi D, Desideri G, Necozione S, Lippi C, Casale R, Properzi $\mathrm{G}$, Blumberg JB, Ferri C: Blood pressure is reduced and insulin sensitivity increased in glucose-intolerant, hypertensive subjects after 15 days of consuming high-polyphenol dark chocolate. J Nutr 2008;138:1671-1676. 


\section{This article has been cited by:}

1. Juan A. Rendón-Huerta, Bertha Juárez-Flores, Juan M. Pinos-Rodríguez, J. Rogelio Aguirre-Rivera, Rosa E. DelgadoPortales. 2011. Effects of Different Sources of Fructans on Body Weight, Blood Metabolites and Fecal Bacteria in Normal and Obese non-diabetic and Diabetic Rats. Plant Foods for Human Nutrition . [CrossRef]

2. David Sánchez, Mar Quiñones, Leila Moulay, Begoña Muguerza, Marta Miguel, Amaya Aleixandre. 2011. Soluble fiberenriched diets improve inflammation and oxidative stress biomarkers in Zucker fatty rats. Pharmacological Research 64:1, 31-35. [CrossRef]

3. L. Fernández-Murga, J.J. Tarín, M.A. García-Perez, A. Cano. 2011. The impact of chocolate on cardiovascular health. Maturitas . [CrossRef] 